Caligrama, Belo Horizonte, v.20, n.1, p. 109-124, 2015

\title{
Dominando a imagem: funções da pintura na narrativa
}

\section{Dominating the picture: the painting functions in the narrative}

Sophie Bertho

Vrije Universiteit Amsterdam, Amsterdam, Holanda

Universität Freiburg, Breisgau, Alemanha

s.bertho@let.vu.nl

Resumo: Este artigo tem por objetivo examinar as referências ao pictural na literatura e, especialmente, definir as funções da presença do quadro de pintura na narrativa. Com base na obra de Marcel Proust, À la Recherche du temps perdu, são analisadas as referências à pintura para se definir quatro tipos de função: psicológica, retórica, estrutural e ontológica, que são exemplificadas com excertos de Proust e comparadas a outras obras da literatura francesa. Conclui-se que as diferentes funções que a referência ao pictural exerce em um romance se distinguem por operarem no nível da recepção ou da produção, sendo que a função ontológica, a mais complexa, ultrapassa essa distinção e atinge o metadiscurso, revelando em uma outra arte, a pintura, a essência da arte primeira, a literatura.

Palavras-chave: arte; pintura; Marcel Proust.

Abstract: This essay investigates the pictorial references in literature and especially defines the role of the presence of paintings in the narrative. These pictorial references are analyzed in order to define four types of functions: psychological, rhetorical, structural and ontological, which are exemplified with Proust excerpts and compared to other works of French literature. The different functions of the pictorial references are 
operating in the novel at reception or production level, and by Proust the ontological function, more complex, beyond this distinction reaches metadiscourse, revealing in another art, painting, the essence of the first art, literature.

Keywords: art; painting; Marcel Proust.

Recebido em 16 de outubro de 2015 Aprovado em 26 de outubro de 2015

\section{1}

A literatura esquece que a pintura demanda ser vista, e não lida. A exigência específica da pintura - exigência que nos satisfaz - é a contemplação, bem antes da ordem das palavras.

A literatura desvia a pintura de sua essência primordial. Jean Roudaut ${ }^{1}$ mostra muito bem como a literatura fala de pintura "para a pressionar a falar", enquanto seu "caráter próprio, fundamental, é justamente estar lá, absolutamente presente, totalmente satisfatória" (ROUDAUT, 1988, p.91). ${ }^{2}$ A literatura rompe com a plenitude silenciosa do quadro, oculta sua especificidade material, sua opacidade.

Dois tipos de interpretação do pictural são possíveis, que são, ao mesmo tempo, dois tipos de desvio: no primeiro caso, o escritor, o poeta, se fazem teóricos, críticos de arte. Neste caso, de fato, a literatura fala de pintura, mas para falar de si mesma. O comentário pictural tal qual o encontramos nos inúmeros escritos sobre a pintura, nesse gênero literário muito particular que é o relato de Salões, é, na verdade, como o mostrou Aron Kibédi Varga (1985, p. 19-34), poética disfarçada, metadiscurso poético. ${ }^{3}$ Fromentin, em Les Maîtres d'autrefois [Os mestres de outrora], fornece um brilhante exemplo com a surpreendente descrição da Crucificação de Rubens, descrita como "uma página de pura expressão

\footnotetext{
${ }^{1}$ Nas páginas seguintes, refiro-me frequentemente à excelente obra de Jean Roudaut, Une ombre au tableau (1988), que aborda de muito perto os problemas de que tratarei aqui. ${ }^{2}$ [No original: "pour presser à parler" (...), "son caractère propre, fondamental, est d'être là, absolument présente, totalement satisfaisante".]

${ }^{3}$ Ver também, sobre esse assunto, La Critique artistique, un genre littéraire. Rouen: Publications de l’Université de Rouen, P.U.F, 1983.
} 
(...) escrita de uma ponta à outra no modo denominado pela retórica de sublime" (FROMENTIN, 1914, p. 89). ${ }^{4}$

No segundo caso, o pictural não é o objeto de um ensaio, ou seja, de um texto independente do escritor; este o insere em um gênero literário existente, sobretudo no romance. Há séculos ${ }^{5}$ os romancistas têm recorrido ao quadro de pintura (fictício ou real) em certos momentos cruciais da narrativa: o quadro, por sua própria imobilidade, ocupa pontos estratégicos no discurso fugidio da narrativa. ${ }^{6}$ De acordo com o efeito pretendido - e que, do mesmo modo, determina o grau de desvio imposto ao quadro em questão - podemos distinguir quatro funções: a função psicológica, a função retórica, a função estrutural e a função ontológica. Examinarei essas quatro categorias principais na obra de Marcel Proust e seguirei a ordem indicada - por ser progressiva -, cujo sentido se revelará no final.

\section{2}

Quando o romancista confere à pintura uma função psicológica, seu interesse específico ainda é mínimo, pois está totalmente submetido à personagem.

A referência pictural substitui ou reforça a voz narrativa, atuando como elemento de caracterização de uma personagem ou de um determinado meio. Quando Swann, por exemplo, se lembra de Bloch porque ele se parece com o Retrato de Maomé II por Bellini (PROUST, 1954, II, p. 97), o leitor é imediatamente informado: Swann é um conhecedor da arte, um esteta. A referência pictural colocada na fala de Swann se torna citação, idioma característico e caracterizante, do mesmo modo que a linguagem utilizada por Françoise. Quando, ainda em À la Recherche du temps perdu [Em busca do tempo perdido], Monsieur

\footnotetext{
${ }^{4}$ [No original: “une page de pure expression (...) écrite d'un bout à l'autre sur ce mode rhétoriquement appelé sublime."]

${ }^{5}$ Pensamos, por exemplo, nas duas cenas célebres, e que se fazem eco, em La Princesse de Clèves: a do retrato da princesa subtraído pelo duque de Nemours e a do retrato do duque observado pela princesa que, por sua vez, é observada por ele.

${ }^{6}$ Para uma comparação desconstrutivista dos retratos pintados e dos retratos escritos, cf. F. Metezer (1987). De uma maneira geral, a respeito de quadros inseridos em uma narrativa, consultar o inventário histórico de B. Dieterle (1988). Sobre as relações entre literatura e pintura narrativa, cf. W. Steiner (1988).
} 
de Norpois entende que as flores pintadas por Fantin-Latour "não se comparam com as de Mme de Villeparisis, nas quais [ele] reconhece mais facilmente as cores da flor" (PROUST, 1954, II, p. 274), "é o "vazio" sobre o qual se apoia o gosto artístico das pessoas mundanas que, por meio de tal interpretação, Proust torna visível ao leitor. ${ }^{8}$

Ao colocar uma referência pictural nas palavras de sua personagem, fazendo-o interpretar um quadro, comparando-o com uma figura pictural localizável para o leitor, o romancista evita o peso, o caráter insistente ou artificial que poderia causar um comentário, indicações psicológicas ou outros. Por outro lado, se essas indicações parecem abstratas, o recurso ao pictural possui a imensa vantagem de fazer "ver" e, portanto, de concretizar, de tornar verossímil.

Os trunfos de tal procedimento aparecem ainda mais claramente em L'Assomoir [A taverna], de Zola, durante a visita ao Louvre feita pelo cortejo nupcial: (pseudo) objetividade por parte do narrador, profundidade atribuída aos personagens; neste caso, é o que os personagens não veem nos quadros que observam que revela ao leitor sua ingenuidade e seu lamentável realismo:

Gervaise perguntou sobre o tema das Bodas de Caná; era uma bobagem não colocar os temas sobre as molduras; Coupeau parou diante da Mona Lisa, na qual encontrou uma semelhança com uma de suas tias. Boche e Bibi la Grillade riam, mostrando-se, com o canto dos olhos, as mulheres nuas; as coxas de Antíope, sobretudo, causaramlhes um sobressalto (ZOLA, 1960, p. 45). ${ }^{9}$

${ }^{7}$ [No original: "[les fleurs] ne peuvent pas soutenir la comparaison avec celles de Mme de Villeparisis où [il] reconnaît mieux le coloris de la fleur."]

${ }^{8}$ Faço referência aqui a M. Proust, $A$ la Recherche du temps perdu, Coll. de la Pléiade, P. Clarac et A. Ferré éds., Paris, Gallimard, 1954. Com efeito, é curioso constatar que inúmeros trabalhos insistem sobre a importância da pintura na obra de Proust, mas muito poucos estudam de perto o papel da pintura para a narração proustiana. Além das obras citadas nas outras notas, deve ser consultado ainda o livro de P. Boyer dedicado a Vermeer na obra de Proust (1987).

${ }^{9}$ Consultar igualmente sobre o tema deste texto, o comentário da obra já citada de J. Roudaut, em particular quando ele designa os participantes das bodas (que só retêm do quadro o "tema") como uma caricatura do "escritor antes de tudo sensível ao que, na obra pictural, permitirá produzir um discurso." (1988, p. 53-54). [No original: "Gervaise demanda le sujet des Noces de Cana; c'était bête de ne pas écrire les sujets sur les 
A função retóric $a^{10}$ pode ser definida como o efeito persuasivo ou afetivo que uma pintura exerce sobre um dos personagens da narrativa, com todas as consequências que se pode imaginar: conversão da personagem, transformação de seus interesses, de suas opiniões ou de suas paixões. O quadro adquire então o status de um actante, adjuvante ou oponente.

La Recherche du temps perdu oferece um exemplo fascinante de uma transformação narrativa gerada por uma pintura. E sua semelhança com a Séfora de Botticelli que desperta em Swann o amor por Odette, uma Odette que, no início, the era indiferente. Pois lembremos que as preferências de Swann se dirigem às "mulheres de beleza bastante vulgar", como a da pequena operária "viçosa e roliça como uma rosa" (PROUST, 1954, I, p. 192 e 218) pela qual ele está apaixonado. ${ }^{11}$ Do rosto mais tarde adorado de Odette, Swann retém o aspecto deplorável de suas bochechas, "que ela frequentemente exibia amareladas e murchas, algumas vezes salpicada de pequenos pontos vermelhos" (PROUST, 1954, I, p. 222). ${ }^{12}$ Com efeito, antes de se tornar para Swann, conforme a melancólica fórmula que encerra o amor, uma mulher "que não era o seu tipo", Odette é, antes de tudo, uma mulher em desacordo com o seu desejo: "Ela aparecera para Swann não sem beleza, decerto, mas

cadres; Coupeau s'arrêta devant la Joconde, à laquelle il trouva une ressemblance avec une de ses tantes. Boche et Bibi la Grillade ricanaient en se montrant du coin de l'œil les femmes nues, les cuisses de l'Antiope surtout leur causèrent un saisissement."] ${ }^{10}$ Sobre a função retórica da imagem em geral, consultamos a notável análise de A. Kibédi Varga (1989).

${ }^{11}$ Notemos que, em La Recherche du temps perdu, a beleza-saúde, harmoniosa, plena (a beleza ao estilo de Rubens!) é sempre uma beleza vulgar e desvalorizada. A verdadeira beleza em Proust, aquela que fascina, é uma beleza móvel, "movente", marcada pelas metamorfoses que a habitam. É uma beleza que dá espaço ao pensamento (não uma beleza sensual) e que daí mesmo retira sua sedução. Daí a importância em La Recherche da pintura renascentista italiana (Bellini, Giotto, Carpaccio), esta "pintura da ideia" como o escreveu Yves Bonnefoy (1967, p. 20). O leitor atento compreenderá que eu não concordo com a noção de beleza que propõe Jean-Pierre Guillerm ao iniciar a análise da pintura na obra de Proust. Sobre o assunto, cf. J. P. Guillerm (1986, em especial p. 134, 135, 138, 153). [No original: "des femmes de beauté assez vulgaire", (...) "fraîche et bouffie comme une rose".]

${ }^{12}$ [No original: "qu'elle avait si souvent jaunes, languissantes, parfois piquées de petits points rouges".] 
de um tipo de beleza que lhe era indiferente, que não the inspirava nenhum desejo, e até mesmo causava-lhe uma espécie de repulsa física" (PROUST, 1954, I, p. 195). ${ }^{13}$

A descoberta da semelhança de Odette com a Séfora de Botticelli é decisiva: ela opera uma mudança radical na alma de Swann e, consequentemente, marca profundamente o desenvolvimento da narrativa. A repulsa se transforma em adoração pela "obra florentina": seu amor foi assegurado a partir do momento em que ele teve "por base os dados de uma estética certeira" (PROUST, 1954, I, p. 224). Não é que Odette pareça mais bela, mas ela subitamente adquire um valor; ela se torna um "exemplar raríssimo", uma peça de museu; Swann se recrimina por ter ignorado o que "teria parecido adorável ao grande Sandro" (PROUST, 1954, I, p. 224). ${ }^{14}$

A função psicológica da pintura se manifesta, então, na aproximação da arte com a realidade; o que se revela é um Swann colecionador, um esteta, um esnobe.

É bastante significativo constatar que, muito mais tarde, em outro momento crítico da narrativa, o caráter negativo e negador de tal atitude não escapará a Marcel, que, vendo-se em uma situação semelhante, se interroga: "Mas não continha o meu quarto uma obra de arte mais preciosa que todas estas? (...) Mas não, de forma alguma Albertine era para mim uma obra de arte. Eu sabia o que era admirar uma mulher de uma maneira artística, eu conhecera Swann" (PROUST, 1954, III, p. 382-83). ${ }^{15}$

O quadro de Botticelli fornece a Swann um "argumento" capaz de transformar a realidade; Marcel, quando recusa seguir a mesma via, utiliza também um procedimento retórico. Swann é um exemplum ao contrário, um exemplo a não ser seguido, o de uma falsa estetização da vida. Swann se detém aquém da arte, enquanto Marcel se torna criador. A função retórica atua como uma advertência: o esteticismo deve ser

${ }^{13}$ [No original: "elle était apparue à Swann non pas certes sans beauté, mais d'un genre de beauté qui lui était indifférent, qui ne lui inspirait aucun désir, lui causait même une sorte de répulsion physique".]

${ }^{14}$ [No original: "l'oeuvre florentine" (...) "pour base les données d'une esthétique certaine" (...), "exemplaire rarissime" (...) "eût paru adorable au grand Sandro".]

${ }^{15}$ [No original: "Mais ma chambre ne contenait-elle pas une cuvre d'art plus précieuse que toutes celles-là? (...) Mais non; Albertine n'était nullement pour moi une œuvre d'art. Je savais ce que c'était que d'admirer une femme d'une façon artistique, j'avais connu Swann."] 
superado para dar lugar à criação. Os dois exemplos se completam, o efeito negativo de uma retórica da persuasão convoca uma retórica da dissuasão: eles constituem assim uma espécie de construção narrativa na qual os elementos retóricos se transformam em elementos estruturais.

A função estrutural da pintura, a mais frequentemente utilizada pelo romancista, é uma função reflexiva. Desta forma, ela corresponde ao que chamamos de mise en abyme. ${ }^{16}$ Ela reflete, resume de forma emblemática certos aspectos da história. Essa função estrutural é geralmente premonitória ou "preditiva", retomando o termo empregado por Roudaut (1988, p. 55): situado no início da narrativa, o quadro de pintura, de alguma maneira, prediz os eventos a seguir.

O leitor de La Recherche du temps perdu se lembrará da descoberta estética de Swann - "como vai a Caridade de Giotto?" - quando compara a ajudante de cozinha da tia Léonie com uma das alegorias do afresco de Giotto que se encontra em Pádua: a criada grávida se parece "bastante com aquelas virgens fortes e corpulentas, matronas, na verdade, nas quais as virtudes são personificadas na Arena" (PROUST, 1954, I, p. 81). ${ }^{17}$

O que importa aqui não é tanto a identidade, em si superficial, que estabelece Swann entre a realidade e a arte, ao encontrar os traços individuais da criada no afresco do grande mestre, mas uma outra analogia que Marcel descobre por trás da primeira. Aquela, sim, é essencial por carregar um saber, por participar da aprendizagem dos signos pelo narrador: a ajudante de cozinha, "gorda", com suas "bochechas flácidas", não corresponde à ideia de maternidade, ela não parece grávida; assim como na alegoria "tão realista" de Giotto, a Caridade é chocante, ela não parece caridosa:

Nenhum pensamento de caridade parece jamais ter sido expresso por seu rosto enérgico e vulgar. Por uma bela invenção do pintor, ela pisoteia os tesouros da terra como

\footnotetext{
${ }^{16}$ No que diz respeito à mise en abyme, indicamos a excelente obra de L. Dällenbach, Le Récit spéculaire. Essai sur la mise en abyme (1977). Ver igualmente a argumentação de M. Bal (1978).

${ }^{17}$ [No original: "en effet assez à ces vierges fortes et homasses, matrones plutôt, dans lesquelles les vertus sont personnifiées à l'Arena".]
} 
se esmagasse uvas para delas extrair o sumo (...); e ela estende a Deus seu coração inflamado, ou melhor, ela o 'entrega' como uma cozinheira passa pelo basculante de seu porão um saca-rolhas a alguém que o solicitara pela janela do térreo (PROUST, 1954, I, p. 80). ${ }^{18}$

O que Marcel compreenderá mais tarde, ou seja, no "agora" do Marcel que se tornou escritor - portanto, tendo encontrado a Verdade, deixado para trás as ilusões da mundanidade e do amor -, é que a ideia da coisa nunca é congruente com a própria coisa.

O mecanismo deceptivo das defasagens entre ideia e coisa, aparência e verdade, mecanismo ${ }^{19}$ ao qual obedecem de maneira quasi sistemática os seres e as coisas de La Recherche du temps perdu, seria então iniciado e anunciado pela alegoria de Giotto, mais exatamente pela interpretação que dela faz Marcel. O afresco é emblemático porque resume; mas é também profético, pois, inserido logo no início da narrativa, anuncia o mecanismo em questão: "a realidade tal qual a sentíramos e que difere tanto do que acreditamos" (PROUST, 1954, III, p. 881). ${ }^{20}$

Os exemplos do que eu chamaria de a experiência da Caridade de Giotto são abundantes em La Recherche du temps perdu. Sabe-se o quanto o devaneio sobre o nome, esse "cratilismo" de que fala Genette, ${ }^{21}$ e as imagens com as quais ele preenche a coisa, antes mesmo que essa coisa tenha se tornado real, será fonte de espanto e decepções reiterados para o narrador: é a ideia de uma Mme de Guermantes, desencarnada, espiritualizada pela poética de seu nome e que Marcel se representa com "as cores de uma tapeçaria ou de um vitral em um outro século, diferente

${ }^{18}$ [No original: “Aucune pensée de charité ne semble avoir jamais pu être exprimée par son visage énergique et vulgaire. Par une belle invention du peintre elle foule aux pieds les trésors de la terre, mais absolument comme si elle piétinait des raisins pour en extraire le jus (...); et elle tend à Dieu son cour enflammé, disons mieux, elle le lui 'passe' comme une cuisinière passe un tire-bouchon par le soupirail de son sous-sol à quelau'un qui le lui demande à la fenêtre du rez-de-chaussée."]

${ }^{19}$ Esse mecanismo corresponde ao que Barthes denomina "a inversão". Cf. R. Barthes (1980). Sobre o tema do movimento repetitivo, estruturador de La Recherche, das decepções-revelações, cf. a reconhecida obra de G. Deleuze, Proust et les signes (1964), em especial o capítulo intitulado "L'Aprentissage", p. 36-50.

${ }^{20}$ [No original: "la réalité telle que nous l'avons sentie et qui diffère tellement de ce que nous croyons".]

${ }^{21}$ Penso particularmente em Mimologiques (1976). 
das pessoas vivas" que provoca, face à pessoa real, essa reação: "É isto, é apenas isto, Mme de Guermantes!" (PROUST, 1954, I, p.174-175). ${ }^{22}$ $\mathrm{Ou}$, ainda, as conotações persas do nome moldam a virgem de Balbec que aparece na realidade "metamorfoseada, assim como a própria igreja, em uma pequena velha de pedra, da qual podíamos medir a altura e contar as rugas" (PROUST, 1954, II, p. 660). ${ }^{23}$

Do mesmo modo que a Caridade pode se encarnar - assim como em Giotto - em uma enérgica faxineira, a maternidade sob a aparência volumosa da ajudante de cozinha, o principesco também pode se disfarçar sob um envelope vulgar: aquela que Marcel toma, a princípio, por "alguma proprietária de bordel, uma cafetina em viagem" (PROUST, 1954, II, p. 858 ${ }^{24}$ é a célebre Princesa Sherbakoff, e a pequena dama humilde e modesta com "seu vestido de lã preta e seu chapéu fora de moda" (PROUST, 1954, I, p. 678) 25 $^{25}$ quem zombam os não iniciados do Grande Hotel, é, na verdade, a marquesa de Villeparisis. Essa relação contingente entre ideia de, imagem de, e realidade, simplesmente decepcionante, curiosa no ambiente mundano, se faz revelação cruel no mundo do amor. Pois, em La Recherche, aquele que ama está sempre sob o efeito de uma ilusão, de um erro inicial que as investigações, as descobertas, enfim revelarão; a realidade da mulher amada sendo, a cada vez, como o mostra Deleuze, a da inversão, a do segredo homossexual. Por trás da imagem reconfortante de uma Odette acolhida pelos Verdurin, que vai à sua costureira, que ama os crisântemos, há essas palavras: "talvez duas ou três vezes" que marcam "na carne, uma espécie de cruz no coração" (PROUST, 1954, I, p. 363) ${ }^{26}$ de Swann. Trajeto que repete Marcel com Albertine, metamorfoseada pelo imaginário do amante em seres sempre diferentes, até à terrível frase que lhe escapa: "eu prefiro muito mais que você me deixe de uma vez por todas livre ainda que

${ }^{22}$ [No original: "les couleurs d'une tapisserie ou d'un vitrail dans un autre siècle, d'une autre manière que les personnes vivantes" (...) "C'est cela, ce n'est que cela, Mme de Guermantes!']

${ }^{23}$ [No original: "métamorphosée, ainsi que l'église elle-même, en une petite vieille de pierre dont on pouvait mesurer la hauteur et compterles rides."]

${ }^{24}$ [No original: "quelque tenancière de grande maison de filles, une maquerelle en voyage".]

${ }^{25}$ [No original: "sa robe de laine noire et son bonnet démodé".]

${ }^{26}$ [No original: "peut-être deux ou trois fois" (...) "à vif une sorte de croix dans (le) cour".] 
isso acabe comigo..." (PROUST, 1954, III, p. 337). ${ }^{27}$ A constatação desiludida de Swann - "meu maior amor foi por uma mulher que não me agradava, que não era meu tipo" 28 - é duplicada simetricamente pelo narrador: "a Albertine real, vista na praia (...) nada mais era que uma silhueta, tudo o que nela havia se sobreposto era invenção minha, pois no amor, os acréscimos que vêm de nós mesmos vencem" (PROUST, 1954, I, p. 858). ${ }^{29}$

A experiência deceptiva da Caridade de Giotto tem um papel central em La Recherche porque se opõe estruturalmente a outra experiência, bem conhecida, que é a da madeleine. Essas duas cenas inauguram duas séries paralelas e opostas. Se a experiência da madeleine e a "alegria poderosa à qual está ligada", tornam "as vicissitudes da vida indiferentes, seus desastres inofensivos, sua brevidade ilusória" (PROUST, 1954, I, p. 145) ${ }^{30}$ é essencial, é porque, lembremo-nos, ela revela ao narrador momentos subtraídos ao Tempo, e, a partir daí, sua vocação de escritor; a literatura que converte a matéria (como o faz a memória involuntária, instituindo relações entre realidades distintas) constituindo o único meio de reencontrar o tempo perdido.

A experiência da madeleine (e as equivalentes que lhe sucedem: o pavimento da calçada, o guardanapo), que se liga aos temas da alegria e da literatura, se opõe, portanto, à outra experiência-chave de $L a$ Recherche, a experiência da Caridade de Giotto, aliada à decepção, a todas as "decepções da minha vida, enquanto vivida" (PROUST, 1954, III, p. 877) $)^{31}$ e à realidade.

Um outro aspecto da função estrutural ou "preditiva" se manifesta em uma imagem inserida no célebre romance de Flaubert, Madame Bovary. Esta imagem, cuja importância estratégica eu gostaria de demonstrar, colocada novamente no início da narrativa, anuncia, desta

${ }^{27}$ [No original: "j'aime bien mieux que vous me laissiez une fois libre pour que j'aille me faire casser...".]

${ }^{28}$ [No original: "J'ai eu mon plus grand amour pour une femme qui ne me plaisait pas, qui n'était pas mon genre".]

${ }^{29}$ [No original: "l'Albertine réelle, aperçue sur la plage (...) n'était qu'une silhouette, tout ce qui s'y était superposé était de mon cru, tant dans l'amour les apports qui viennent de nous l'emportent".]

${ }^{30}$ [No original: "joie puissante qui y est liée" (...) "les vicissitudes de la vie indifférente, ses désastres inoffensifs, sa brièveté illusoire".]

${ }^{31}$ [No original: "déceptions de ma vie, en tant que vécue".] 
vez, todo o destino de uma personagem, no caso, Emma Bovary, e sua sujeição a um outro que poderíamos designar como sendo a Doxa.

Lembraremo-nos da cena da hospedaria, ocorrida antes da chegada de Emma no convento. A incongruidade semântica da frase: "eles foram servidos, no jantar, com pratos decorados", capta a atenção do leitor e, ao mesmo tempo, assinala que a instância narrativa abarca, neste caso, a visão de Emma, sublinhando, ao mesmo tempo, a importância do prato quanto à constituição da personagem:

Quando completou treze anos, seu próprio pai a levou à cidade para interná-la no convento. Eles pararam em uma hospedaria do bairro Saint-Gervais, onde foram servidos, no jantar, com pratos decorados com desenhos representando a história de Mlle de La Vallière: as explicações da lenda, cortadas aqui e ali pelos arranhões das facas, glorificavam, todas elas, a religião, as delicadezas do coração e as pompas da Corte (FLAUBERT, 1966, p.70) ${ }^{32}$

Reunindo romanesco e prosaico, para permanecer no registro do medíocre (que é o da vida de Emma Bovary), do clichê, ${ }^{33}$ os pratos pintados testemunham ironicamente o destino da personagem, resume os modelos (religião, amor, luxo) que ela se esforçará para reproduzir ao longo da narrativa. Emma não se tornará essa senhorita de La Vallière, amante de Louis XIV, grande apaixonada, grande penitente, mas, sim, a senhorita de La Vallière kitsch, revista e reescrita pela doxa - Flaubert diria, a Estupidez -, exatamente a La Vallière do prato pintado.

Religião, amor, luxo: vejamos como a narrativa desenvolve os modelos anunciados pela louça. Emma Bovary, como se sabe, vive no convento uma fase de pseudo misticismo, confundindo a religião com suas

\footnotetext{
32 [No original: "Lorsqu'elle eut treize ans, son père l'amena lui-même à la ville, pour la mettre au couvent. Ils descendirent dans une auberge du quartier Saint-Gervais, ou ils eurent à leur souper des assiettes peintes qui représentaient l'histoire de Mlle de La Vallière: Les explications légendaires, coupées ça et là par l'égratignure des couteaux, glorifiaient toutes la religion, les délicatesses de cour et les pompes de la Cour."] ${ }^{33} \mathrm{O}$ prato pintado é, com efeito, marcado pelo trabalho de um clichê no sentido literal da palavra: uma placa com o relevo da reprodução de uma imagem que permite a impressão de vários exemplares. Sublinhamos, por outro lado, a importância do clichê na prosa flaubertiana. Sobre o clichê em Flaubert e suas funções, ver em particular R. Amossy e E. Rosen (1982).
} 
"relíquias", orando não para Deus, mas adorando "as imagens religiosas emolduradas de azul", nas quais se vê o "cordeiro adoentado", "o sagrado coração cravado de flechas" (FLAUBERT, 1966, p.70), ${ }^{34}$ imagens piegas que remetem àquelas representadas no prato. As "delicadezas do coração" (sublinhamos aqui o clichê) representadas no prato do restaurante e que Emma reencontra no convento na forma também barata das gravuras de keepsakes - damas "devaneando sobre sofás, ao lado de uma carta aberta", lua, lágrimas derramadas, margarida desfolhada (FLAUBERT, 1966, p.72-73), ${ }^{35}$ metonímias ingênuas e retorcidas do amor -, anunciam a busca desesperada da paixão romanesca, os adultérios, o irrisório arrebatamento de Emma: "eu tenho um amante, um amante" (FLAUBERT, 1966, p. 191). ${ }^{36}$ Enfim, são as "pompas da Corte", reiteradas na ocasião do baile em Vaubyessard, com as conhecidas consequências - "o baila cavara um fosso em sua vida" (FLAUBERT, 1966, p. 80) ) $^{37}$, para, em seguida, levar às loucas despesas de Emma; pompas, faustos lamentáveis entregues a domicílio pelo Senhor Lheureux, o vendedor de tecidos.

Flaubert, ao escolher o suporte grosseiro do prato (e não a tela), o ambiente prosaico da hospedaria (e não o castelo) e a imagem da grande dama de La Vallière (representando uma imagem kitsch, emblemática de Emma), indicaria, por isso mesmo e mais uma vez, as defasagens ao mesmo tempo grotescas e trágicas: sonhos elevados, ideais romanescos de um lado e realidade tomada pela mediocridade de outro lado, marcam o destino de sua heroína. O prato pintado (arranhado pelas facas dos comensais!) no lugar do quadro de pintura, inaugura a sequência: Charles Bovary, médico fracassado no lugar do genial inventor, amantes frios e covardes no lugar das "palavras de felicidade, paixão e euforia" (FLAUBERT, 1966, p.69), ${ }^{38}$ feira dos Comícios e mugidos do gado como cenário dos primeiros momentos de paixão de Emma por Rodolphe. A própria morte de Emma foge ao desejado ideal romântico, eclipsada pela canção obscena do cego, canção que, inclusive, assim como as imagens religiosas e as gravuras dos keepsakes, inscrevem-se mais uma vez no

\footnotetext{
${ }^{34}$ [No original: "les vignettes pieuses bordées d'azur", "la brebis malade", "le sacré cour percé de flèches".]

${ }^{35}$ [No original: "rêvant sur des sofas près d'un billet décacheté".]

${ }^{36}$ [No original: "J'ai un amant, un amant".]

${ }^{37}$ [No original: "le bal avait fait un trou dans sa vie".]

38 [No original: "mots de félicité, de passion et d'ivresse".]
} 
registro do trivial, enquadrado em toda essa quinquilharia - que fascinava Flaubert - do tesouro endoxal, o prato constituindo seu primeiro objeto.

\section{5}

Terminarei pelo que denominei de função ontológica ${ }^{39}$ da pintura. O quadro aqui não possui mais seu estatuto narrativo como no caso da função estrutural; ele se imobiliza em uma descrição que simboliza o sentido da própria obra. Em La Recherche, a pintura de Elstir assume esta função, e é notável o fato de se tratar de quadros não existentes na realidade, mesmo se suas descrições apresentam traços reconhecíveis em obras de Turner e de Monet. A pintura de Elstir é uma verdadeira pintura da escrita, de escritor.

O que o narrador descobre, maravilhado, nas marinhas de Elstir, é que a "essência" do mar não se encontra obrigatoriamente no mar. Nas marinhas de Elstir, a representação obedece, não à lógica do real, mas à primeira impressão do olhar, que é, ao mesmo tempo, sempre ilusão de ótica. Para pintar Le Port de Carquehuit, Elstir troca o marinho pelo terrestre: o mar tornou-se "rural", as igrejas parecem "sair das águas", "os barcos estão atrás da cidade" (PROUST, 1954, II, p. 836), ${ }^{40}$ a demarcação habitual, lógica, entre a terra e o oceano, desapareceu.

Reencontramos, assim, na pintura de Elstir, nessas "metamorfoses", a relação metafórica ${ }^{41}$ fundada na analogia que domina a escrita proustiana. Lembraremos aqui as inúmeras equivalências, com base no "sensível", nas quais a essência das coisas e dos seres é então apreendida, nas quais sua verdadeira estética é revelada, de acordo com esta mesma confusão ótica que marca os quadros de Elstir: Veneza faz surgir Combray, Balbec remete a Veneza, a música de Vinteuil evoca um

\footnotetext{
${ }^{39}$ Prefiro falar de função ontológica, pois se trata de uma revelação pelo quadro do ser das coisas e do mundo representados na narrativa, ao invés da expressão "ilustração da mecânica do livro", usada por Roudaut (1988, p.63), na obra já citada, para ilustrar o mesmo fenômeno.

${ }^{40}$ [No original: "sortir des eaux", "les bateaux sont derrière la ville".]

${ }^{41}$ No que se refere à metáfora nos quadros de Elstir, ver o notável artigo de C. Malabou (1988); a análise de J. Roudaut (1988, p. 63-65); L.M. Johnson (1980); o capítulo intitulado "Le Port de Carquehuit" de M. Butor (1964); M. Pleynet (1988); A. Henry (1981); e no que se refere à metáfora em geral em Proust, cf. "Proust palimpseste" de G. Genette (1966).
} 
passeio no bosque de Boulogne, Albertine está ligada ao mar, a senhorita de Stermaria à Bretanha. Pois, diz Proust, a beleza de uma coisa só pode ser conhecida em uma outra (PROUST, 1954, III, p. 889), apenas através de seu equivalente sensível (e não graças à uma "explicação material"). Deleuze (1964, p. 21-22) mostrou com sutileza como as equivalências, da qual a metáfora é uma forma, pictural ou literária, por meio das transmutações que efetuam, espiritualizam a matéria, arrancam-na à sua opacidade inicial.

A pintura de Elstir sintetiza, simboliza a poética proustiana. As metáforas que usam o pintor e o escritor são bem mais que uma técnica. Elas são visão, no sentido de revelação:

$\mathrm{O}$ pintor original, o artista original, agem à maneira dos ocultistas. O tratamento de sua pintura, de sua prosa, nem sempre é agradável. Quando está terminado, o profissional nos diz: agora, olhe. Eis que o mundo (que não foi criado uma vez, mas sempre que um artista original apareceu) surge-nos inteiramente diferente do antigo, mas perfeitamente claro (PROUST, 1954, II, p. 327). ${ }^{42}$

Tudo o que é mencionado ou escrito em uma narração, com exceção dos personagens nela inseridos, possui uma dupla função: os objetos citados ou representados existem para os personagens e eles têm uma existência, não necessariamente a mesma, para o leitor. Frequentemente, este interpreta o interesse de tal objeto quando a personagem está tão implicada na intriga que não pode perceber claramente esse interesse, $o$ verdadeiro valor, para ele, do objeto representado. As diferentes funções que os quadros exercem em um romance se distinguem, ainda assim, pois certas funções operam sobretudo no nível do leitor, outros, no interior da narrativa. A função retórica, tal como foi exposta, é uma função interna; ela diz respeito em primeiro lugar à personagem: é Swann que se deixa persuadir pelo quadro de Botticelli; o leitor apenas constata, em seguida, os efeitos. Em contrapartida, as funções psicológicas e estruturais interessam diretamente o leitor: é ele que percebe o nível cultural de

\footnotetext{
${ }^{42}$ [No original: “le peintre original, l'artiste original procédent à la façon des occultistes. Le traitement par leur peinture, par leur prose, n'est pas toujours agréable. Quand il est terminé, le praticien nous dit: Maintenant regardez. Et voici que le monde (qui n'a pas été créé une fois, mais aussi souvent qu'un artiste original est survenu) nous apparaît entièrement différent de l'ancien, mais parfaitement clair.']
} 
Gervaise ou o sentido dos pratos pintados; Gervaise e Emma ignoram o que sabe o leitor (ou, no segundo caso, saberá!).

A função ontológica, enfim, representa uma relação de outro modo complexa: ao revelar em uma outra arte - a pintura - a essência da arte primeira - a literatura -, ela designa a essência da vida. Ao mesmo tempo em que se aproxima desse outro metadiscurso tratado no princípio deste estudo, o discurso sobre a pintura e o quadro ultrapassa o dualismo personagem-leitor, torna-o inoperante e solicita ao mesmo tempo o narrador, a personagem e o leitor: o sentido atinge a essência, a arte preenche a vida.

Se o romance se tornou - retomando uma fórmula de Lukács - a forma literária privilegiada de um mundo abandonado pelos deuses, o quadro, descrito, citado, ocupa sem dúvida no romance a mesma função que a imagem verdadeira, vista e admirada, ocupava nas catedrais. A imagem remete ao que comanda o silêncio, à uma essência indizível.

Tradução de Márcia Arbex e Izabela Baptista do Lago.

BERTHO, Sophie. Asservir l'image, fonctions du tableau dans le récit. In: HOEK, Leo H. (Dir.). L'interprétation détournée. Amsterdam, Atlanta, GA: Rodopi, Crin 23, 1990. p. 25-36.

\section{Referências}

AMOSSY R.; ROSEN, E. Les Discours du clichê. Perpignan: CDU, SEDES, 1982. p. 66-82.

BAL, M. Mise en abîme et iconicité, Littérature, n. 29, p. 116-128, fev. 1978.

BARTHES, R. Une idée de recherche. In: GENETTE, G.; TODOROV, T. (Éds.). Recherche de Proust. Paris: Seuil, 1980. p. 34-39.

BONNEFOY, Y. Un rêve fait à Mantoue. Paris: Mercure de France, 1967.

BOYER, P. Le Petit Pan de mur jaune. Paris: Seuil, 1987.

BUTOR, M. Le Port de Carquehuit. In: BUTOR, M. Répertoire II. Paris: Minuit, 1964. p. 265-281

DÄLLENBACH L. Le Récit spéculaire. Essai sur la mise en abyme. Paris: Seuil, 1977. 
DELEUZE, G. Proust et les signes. Paris: P.U.F., 1964.

DIETERLE, B. Erzählte Bilder. Zum narrativen Umgang mit Gemälden. Marburg: Hitzeroth, 1988.

FLAUBERT, G. Madame Bovary. Paris: Garnier-Flammarion, 1966.

FROMENTIN, E. Les Maîtres d'autrefois. Paris: Plon, 1914.

GENETTE, G. Mimologiques. Paris: Seuil, 1976.

GENETTE, G. Proust palimpseste. In: GENETTE, G. Figures. Paris: Seuil, 1966. p. 39-67.

GUILLERM. J.-P. Le Goût de la peinture. In: GUILLERM. J.-P. (Éd.). Des mots et des couleurs II. Lille: Presses Universitaires de Lille, 1986. HENRY, A. Marcel Proust, Théories pour une esthétique. Genève: Klincksieck, 1981. p. 285-302.

JOHNSON, L. M. The Metaphor of Painting, Essays on Baudelaire, Ruskin, Proust and Pater. Ann Arbor: VMI Research Press, 1980.

KIBEDI VARGA, A. Discours, récit, image. Bruxelles: Mardaga, 1989.

KIBEDI VARGA, A. Un métadiscours indirect: le discours poétique sur la peinture. CRIN: La littérature et ses doubles, Amsterdam, Atlanta, n.13, p. 19-34, 1985.

MALABOU, C. Peindre la mer par l'autre sens: Proust et Elstir. Word and Image, v. 4, n.1, p. 195-199, janvier-mars 1988.

METEZER, F. Salomé and The Dance of Writing. Chicago-Londres: University of Chicago Press, 1987.

PLEYNET, M. Regarder l'art moderne (La Recherche). Cahiers $d u$ Musée national d'art moderne. Paris, Centre Pompidou, n. 24, p. 97-112, été 1988.

PROUST, M. À la Recherche du temps perdu. Paris: Gallimard, 1954. Volumes I, II, III. (LColl. de la Pléiade)

ROUDAUT, J. Une ombre au tableau. Rennes: Ubacs, 1988.

STEINER, W. Pictures of Romance. Chicago-Londres: University of Chicago Press, 1988.

ZOLA, E. L'Assomoir. Paris: Gallimard, 1960. (La Pléiade) 